\title{
FutureJournal
}

\section{O Uso de Simulação Baseada em Agentes no Estudo da Adaptação de Organizações no Ambiente Internacional}

\author{
Leonardo Yuji Tamura \\ Mestrandro em Administração pela Escola Superior de Propaganda e Marketing, ESPM, Brasil. \\ leotamura@gmail.com \\ Júlio César Bastos de Figueiredo \\ Professor da Escola Superior de Propaganda e Marketing, ESPM, Brasil. \\ jfigueiredo@espm.br
}

\section{RESUMO}

Neste trabalho, o objetivo é aprofundar o entendimento do processo de adaptação de empresas ao ambiente internacional. Para isso, utilizaram-se estudos que encararam a empresa como um sistema adaptativo complexo e utilizou-se o modelo NK de Stuart Kauffman. O modelo $\mathrm{NK}$, originalmente concebido na biologia, vem sendo aplicado por acadêmicos em trabalhos de estratégia e organizações desde 1997. Para possibilitar seu uso para o estudo de empresas multinacionais, o modelo foi estendido para abarcar conceitos específicos de negócios internacionais como, por exemplo, a obtenção de vantagem competitiva em diferentes países a partir da adaptação de características internas da empresa ao ambiente local. A metodologia utilizada foi baseada no paradigma da modelagem e simulação baseada em agentes, segundo o qual as empresas foram modeladas como agentes autônomos que, por meio de um processo de adaptação buscam otimizar sua vantagem competitiva. Essa abordagem permite estudar propriedades emergentes do sistema a partir da interação e do comportamento dos agentes. Os resultados das simulações mostraram que a obtenção de vantagem competitiva a partir dos atributos organizacionais da empresa em diversos países possibilita o surgimento de novas formas organizacionais viáveis. Também se observou que uma forma organizacional que não propicia vantagem competitiva ótima em um país específico, 


\section{FutureJournal}

ainda pode ser viável num contexto global. Outro resultado obtido foi a emergência da catástrofe da complexidade, que é a degradação da vantagem competitiva em decorrência da adição de restrições conflitantes. Tais restrições conflitantes são resultado da necessidade de otimizar simultaneamente a vantagem competitiva em diversos países de várias formas diferentes devido à possibilidade de adaptação local.

PALAVRAS-CHAVE: Estratégia internacional. Adaptação. Modelo NK. Modelagem baseada em agentes.

\section{The use of simulation based on agents in the study of the adaptation of organizations in the international environment}

\section{ABSTRACT}

The objective of this study is to deepen the understanding of the process of adaptation of companies in the international environment. Studies that consider the company as a complex adaptive system were used, and the NK model by Stuart Kauffman was the based for the study. The NK model, originally conceived in Biology, has been applied by scholars in strategy and organizations since 1997. In order to enable the use of this model for the study of multinational companies, the model has been extended to encompass specific concepts of international business such as, for example, to ability to obtain competitive advantage in different countries with the adaptation of internal characteristics of the company to the local environment. The methodology used was based on the paradigm of modeling and simulation based on agents, according to which companies were modeled as autonomous agents who, through a process of adaptation aim at optimizing their competitive advantage. This approach allows to study emerging 


\section{FutureJournal}

properties of the system from the agents' interaction and behavior. The simulation results showed that the achievement of competitive advantage from the company's organizational attributes in several countries enables the emergence of viable new organizational forms. It was also observed that an organizational form that does not provide competitive advantage in a specific country, can still be viable in a global context. Another result obtained was the emergence of the disaster of complexity, which is the deterioration of the competitive advantage due to the addition of conflicting constraints. Such conflicting restrictions are a result of the need to simultaneously optimize the competitive advantage in various countries in several distinct ways due to the possibility of local adaptation.

KEY-WORDS: International Strategy, Adaptation, NK Model, Modeling Based on Agents. 


\section{INTRODUÇÃO}

O estudo de negócios internacionais contempla a investigação de como as multinacionais se configuram internamente para criar vantagem competitiva e estar aptas a competir globalmente (Siggelkow \& Levinthal, 2003). Por sua vez, conceitos de sistemas adaptativos complexos permitem uma análise das firmas do ponto de vista de um sistema de atividades interdependentes (Porter \& Siggelkow, 2008) e interações não lineares (Anderson, 1999), em que o comportamento é resultado não só do contexto presente, como também do contexto passado (Anderson, 1999).

Pesquisadores como Porter e Siggelkow (2008) analisaram a firma como um sistema adaptativo complexo para investigar estratégias do tipo follow-the-leader, em que empresas menos aptas ao ambiente copiam a estratégia da empresa líder. Os autores constataram que, em determinadas circunstâncias, os resultados esperados podem não ser obtidos pelas empresas pois, quando há interdependências, se apenas alguns aspectos são imitados, então eventualmente nenhum benefício pode ser gerado (Porter \& Siggelkow, 2008).

De modo similar, utilizando modelagem de sistemas complexos, Caldart e Ricart (2007) demonstraram que, em determinados contextos, é possível suportar a superioridade da colaboração espontânea e autoorganizada entre as unidades de negócio versus uma colaboração restritiva e fortemente acoplada e imposta centralmente.

Dentre os acadêmicos que encararam a firma como um sistema adaptativo complexo, é possível identificar um grupo distinto que utilizou a modelagem e a simulação baseada em agentes em seus trabalhos. Parte desses pesquisadores utilizou o modelo NK de Kauffman (1993) como paradigma de modelo adaptativo evolucionário de empresas. Trata-se de um modelo concebido originalmente para estudar fenômenos biológicos como a evolução, a seleção e a auto-organização. No entanto, em 1997, Levinthal (1997) utilizou o modelo NK em seu artigo para o periódico Management Science, inaugurando o uso do modelo NK para estudos gerenciais (Ganco \& Hoetker, 2009; Wall, 2014). 
Apesar da farta literatura sobre o uso deste modelo NK em estudos de estratégia, ele ainda não foi adaptado para estudar estratégias no contexto internacional. Sabe-se que a multinacional, ao atuar em diferentes países, enfrenta um dilema: ela deve ter adaptabilidade local para atender as especificidades do país, mas também possuir integração e eficiência global (Bartlett \& Ghoshal, 1999).

Tal dilema ocorre porque, caso a firma opte por ter alta adaptabilidade local, apesar de ela possuir um posicionamento extremamente competitivo e vantajoso no país-alvo (Tallman \& Yip, 2001), a multinacional seria um conjunto de negócios autônomos com pouca sinergia, mas com o peso dos custos de uma multinacional, como aconteceu com a Philips e outras multinacionais na década de 1980 e 1990 (Tallman \& Yip, 2001). No outro extremo, caso opte por baixa adaptabilidade local, isso faria a multinacional operar com extrema padronização e eficiência, mas impossibilitaria um posicionamento competitivo e vantajoso no país-alvo.

O objetivo deste trabalho é estender o modelo NK de Kauffman, com o uso do paradigma de programação baseada em agentes, para permitir um melhor entendimento dos processos de adaptação de empresas no ambiente internacional.

Busca-se, por meio da análise dos resultados das simulações, observar o surgimento das desvantagens de ser estrangeiro (liability of foreignness), das empresas multinacionais perante as empresas locais do país de destino; constatar se é possível surgirem novas formas organizacionais viáveis decorrentes da alavancagem de vantagens competitivas de atributos organizacionais em outros países; mostrar que uma forma organizacional que não propicia vantagem competitiva máxima em um país ainda pode ser viável num contexto global; observar a emergência da chamada catástrofe da complexidade; e constatar as relações entre a diferença entre países, o grau de adaptação local e a vantagem competitiva global.

Com este trabalho, busca-se contribuir para o campo de gestão internacional apresentando um modelo que permitirá a outros pesquisadores simular o processo de adaptação em mercados estrangeiros de forma longitudinal e dinâmica. O uso de modelos dinâmicos e 
longitudinais possibilita uma visão mais ampla, novas descobertas e conciliação entre diversas teorias e entre resultados empíricos contraditórios.

\section{REVISÃO TEÓRICA}

\subsection{MULTINACIONAIS E ADAPTAÇÃO}

Na teoria das empresas multinacionais, a necessidade de vantagens especiais já era postulada por Stephen Hymer, em torno de 1960, para que uma firma nacional pudesse ser lucrativa fora de seu país de origem (Teece, 2006). Essas supostas vantagens especiais compensariam ineficiências e custos decorrentes das desvantagens de ser estrangeiro, do inglês liability of foreignness (LOF), das empresas multinacionais perante as empresas locais do país de destino.

As fontes de tais vantagens poderiam ser tanto do potencial do mercado para determinado produto, técnicas de produção superiores, pioneirismo ou mesmo imperfeições no mercado fornecedor, que permitiriam preços mais baixos de aquisição (Teece, 2006), quanto do processo de adaptação aos países onde se instalam.

Nesse contexto, um conceito recorrentemente utilizado na pesquisa de negócios internacionais é a diferença entre países ou locais, que têm definições distintas dependendo do modelo ou teoria adotado. Para o modelo Upsalla (Johanson \& Vahlne, 2009), a diferença entre países é chamada de distância psíquica. Para teorias comportamentais, ela é chamada de distância cultural (Kogut \& Singh, 1988) e medida por um índice composto das dimensões culturais de Hofstede (1980).

A teoria institucional, aplicada ao contexto de empresas multinacionais (MNEs), descreve tal distância em termos das diferenças institucionais formais ou informais (Kostova, Roth \& Dacin, 2008; Berry, Guillén \& Zhou, 2010). Para o paradigma eclético (Dunning \& Lundan, 2008), as diversas diferenças estão nos fatores relacionados à localização (distância física, cultural, políticas, recursos, infraestrutura, mercado 
potencial, etc.) e postula-se que tais fatores podem gerar vantagens quando acompanhados de um processo eficiente de adaptação local.

Perante a diferença entre os países, um maior ou menor nível de adaptação local pode gerar maiores ou menores vantagens à organização. Essa adaptação local pode ser o resultado de (1) deliberação estratégica da empresa ou (2) maior ou menor capacidade de transferência e adaptação de ativos específicos da firma à realidade local.

\subsection{SISTEMAS ADAPTATIVOS COMPLEXOS (CAS)}

A complexidade está presente em pesquisas sobre organizações desde a década de 1960 (Anderson, 1999). Para o campo da estratégia, conceitos da complexidade têm sido utilizados para estudar dilemas como o equilíbrio entre estratégias deliberadas, com ações mais restritas, versus estratégias emergentes menos estruturadas. Esse dilema por vezes é descrito em termos de acoplamentos fortes e fracos entre matrizes e subsidiárias, unidades de negócios, gestores e subordinados e parceiros estratégicos. Nesses estudos, investiga-se a possibilidade da existência de estruturas ótimas que possibilitam tanto eficiência quanto flexibilidade em função do ambiente, sendo este por vezes suscetível a mudanças, incertezas e turbulências (Pina e Cunha, Vieira da Cunha \& Wilding, 2006; Davis, Eisenhardt \& Bingham, 2007).

Uma categoria especial de sistemas complexos é denominada Sistema Adaptativo Complexo (Complex Adaptive System - CAS), que é composto por agentes que se relacionam uns aos outros por laços de realimentação (feedback loops) e, ao interagirem, influenciam-se mutuamente. Isso significa que o comportamento de um agente depende e influencia o comportamento de outros agentes. O resultado dessa interação dá origem ao comportamento agregado do sistema (Holland, 1992) ou propriedades globais do sistema (Miller \& Page, 2009), que não podem ser simplesmente derivadas do comportamento isolado de cada uma das partes, mas da interação delas. Logo, o comportamento de um único agente não dita o comportamento do sistema. 
Esses agentes atuam segundo determinadas regras (schema) ou condições/ações que podem variar entre os agentes com o tempo (Holland, 1992; Anderson, 1999; Davis et al., 2007; Man Joe Ma \& Osula, 2011). Essa variação ao longo do tempo ocorre porque os agentes são capazes de aprender (Holland, 1992). Como o comportamento deles depende do que eles "sabem" e das condições em que se encontram (Man Joe Ma \& Osula, 2011), a forma como respondem ao ambiente se adapta com o tempo (Davis et al., 2007).

Como nesse processo de adaptação cada agente se adéqua ao ambiente na busca de mais recompensas ou aptidão, e tal recompensa ou aptidão depende do próprio agente e dos demais, outra característica dos CAS é a coevolução (Anderson, 1999). O dinamismo dos CAS decorre da evolução dos agentes e também do processo populacional de entrada e saída de agentes (Anderson, 1999).

Os agentes também são capazes de realizar cômputos, como, por exemplo, a antecipação, uma capacidade de processamento em que, dadas determinadas condições, o agente antecipa (estima, prevê) as consequências de determinadas reações (Holland, 1992).

Portanto, os modelos de CAS ajudam a entender como resultados complexos podem surgir de (1) regras simples segundo as quais os componentes do sistema agem e da (2) forma como esses componentes estão interconectados (Anderson, 1999). As características dos sistemas adaptativos complexos formam uma referência muito útil para o desenho de modelos baseados em agentes (Macal \& North, 2009).

\subsection{O MODELO NK DE KAUFFMAN}

As paisagens de aptidão foram originalmente introduzidas pelo biólogo Sewall Wright (1932). Kauffman (1993) definiu o modelo NK, que é a formalização de um método para obtenção das paisagens, e o utilizou para estudar a evolução adaptativa, processo pelo qual os organismos buscam posições de maior aptidão ao ambiente por meio de mutações genéticas. Levinthal (1997) direcionou seu uso para o campo do gerenciamento (Ganco \& Hoetker, 2009; Wall, 2014) e para o estudo do 
processo de adaptação organizacional, que ocorre por meio da mudança de um atributo significativo da organização.

No modelo NK de Kauffman, a aptidão é qualquer propriedade bem definida e sua distribuição pelo espaço (Kauffman, 1993). Embora tenha sido o pioneiro ao aplicar o modelo NK no contexto organizacional, Levinthal (1997) não definiu qual propriedade seria essa. Posteriormente, McKelvey (1999), utilizando o modelo para estratégia organizacional, assume que a aptidão é a vantagem competitiva, resultante das diversas competências organizacionais, que englobam os termos da visão baseada em recursos: recursos, competências centrais, capacidades dinâmicas e o termo "atividade da cadeia de valor" de Porter (Porter, 1991).

No modelo NK, existem dois parâmetros. O parâmetro $\mathrm{N}$ representa o número de partes de um sistema, como os genes de um genótipo (Kauffman, 1993). No contexto organizacional, N é o número de partes, atributos ou decisões de uma organização (Levinthal, 1997; Ganco \& Hoetker, 2009). O parâmetro K é o grau de acoplamento ou interdependência entre as partes ou os diversos atributos da organização (Levinthal, 1997). Assim, um sistema ou organização pode ser caracterizado por um vetor $\mathrm{x}$ de $\mathrm{N}$ valores.

$$
\boldsymbol{x}=\left(\boldsymbol{n}_{1}, \boldsymbol{n}_{2}, \ldots, \boldsymbol{n}_{N}\right)
$$

em que $n_{i}$ é o valor da i-ésima parte do sistema ou atributo organizacional.

Cada um dos atributos pode assumir $A$ diferentes valores, portanto cada paisagem apresenta $A^{N} A^{N}$ locais. Por exemplo, tipicamente é utilizado $A=2$ (Kauffman, 1993; Vidgen \& Padget, 2009), em que os possíveis valores são binários: 0 ou 1 . Se $\mathrm{N}=3$ e $A=2$, a paisagem tem oito locais identificados pelas sequências 000, 001, 010, 011, 100, 101, 110 e 111. Na Erro! Fonte de referência não encontrada., ilustra-se uma paisagem em que $N=6$. O eixo x representa a combinação dos atributos $n_{1}, n_{2}, n_{3}$, o eixo y é a combinação dos atributos $n_{4}, n_{5}, n_{6}$, e o eixo z é a aptidão. Por simplicidade, este trabalho irá adotar $A=2$. 


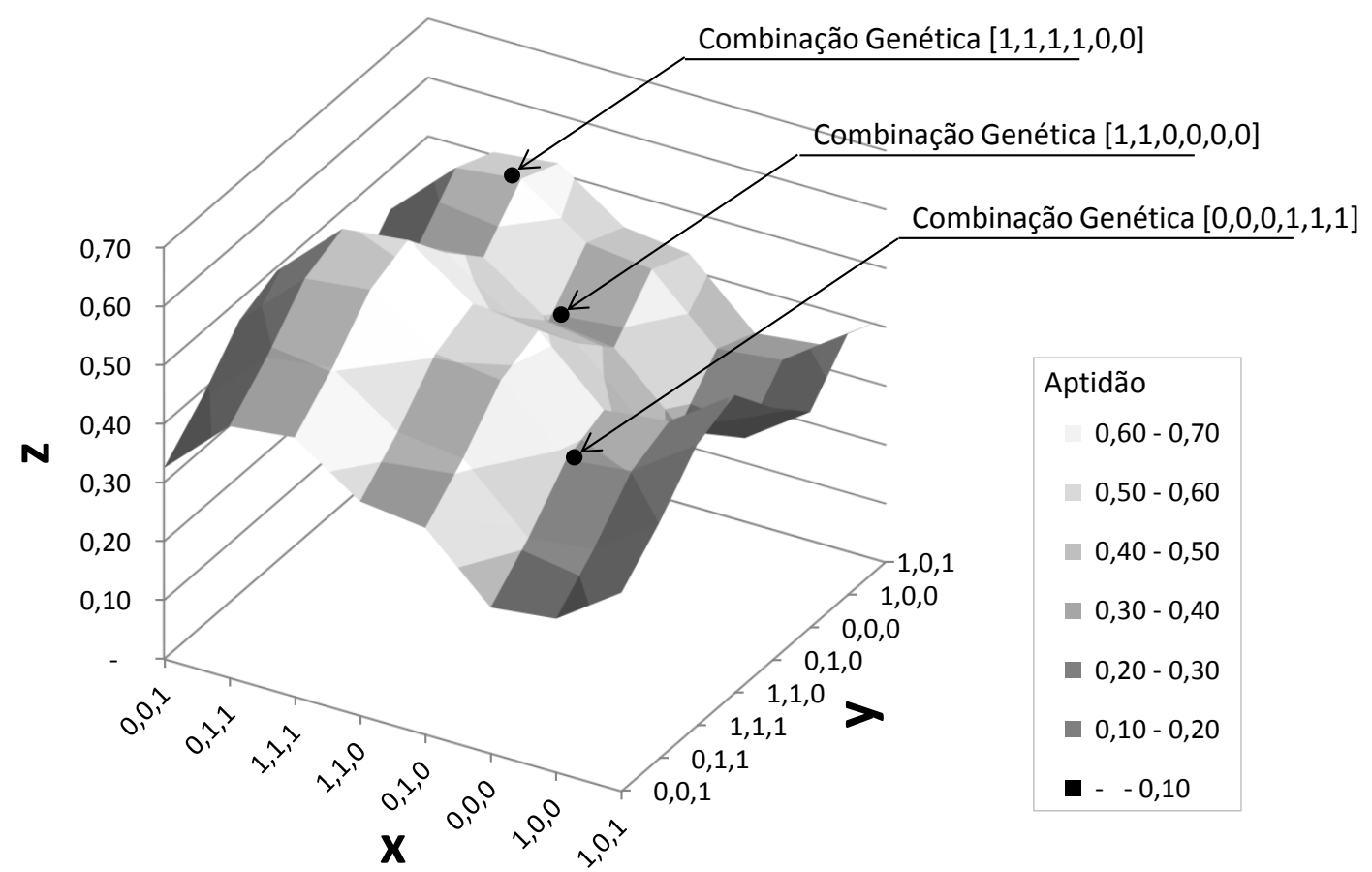

Figura 1: Cada local na paisagem é uma combinação genética representada por uma sequência diferente

Fonte: Elaborada pelos autores

Cada atributo faz uma contribuição $\left(\mathrm{w}_{\mathrm{i}}\right)$ à aptidão da organização que depende da parte $i$ e de $K$ outras partes (Kauffman, 1993). Na Erro! Fonte de referência não encontrada., mostram-se sistemas com diferentes combinações de $N$ e $K$. O parâmetro $K$ reflete o grau de acoplamento entre os atributos. Na genética, $K$ mede o grau de interações epistáticas entre os genes (Kauffman, 1993). Nas organizações, as relações epistáticas foram traduzidas como a interdependência da estratégia da firma e sua estrutura organizacional e como o grau com que diferentes atributos organizacionais se reforçam mutuamente. 


\begin{tabular}{|l|l|l|l|l|}
\hline $\mathrm{n} 1$ & $\mathrm{n} 2$ & $\mathrm{n} 3$ & $\mathrm{n} 4$ & $\mathrm{n} 5$ \\
\hline
\end{tabular}

$\mathrm{N}=5 ; \mathrm{K}=0$

(a)

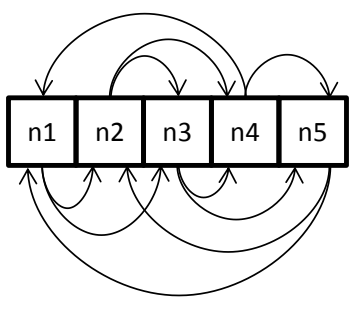

$\mathrm{N}=5 ; \mathrm{K}=2$

(b)

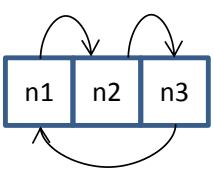

$\mathrm{N}=3 ; \mathrm{K}=1$

(c)

Legenda:

$\mathrm{n}_{\mathrm{i}}$ i-ésima parte do sistema $\curvearrowright$ Relação de dependência entre as partes

\section{Figura 2: Representação de sistemas com $N$ partes $e K$ acoplamentos}

Fonte: Elaborada pelos autores

O conjunto dos possíveis genótipos, chamado de espaço, pode ser representado por um espaço multidimensional. Como o próprio Kauffman reconhece, a representação visual de espaços multidimensionais é difícil. Um artifício utilizado (Ganco \& Hoetker, 2009) é a representação do espaço multidimensional em um espaço bidimensional. Nessa representação, cada eixo possui $2^{N / 2}$ combinações, ordenando vizinhos lado a lado, como mostrado na Tabela 1 . Um vizinho é uma combinação em que o valor de apenas uma das partes é alterado (Kauffman, 1993).

Tabela 1: Distribuição bidimensional de um espaço $N=6, A=2$

$\mathrm{n} 1, \mathrm{n} 2, \mathrm{n} 3$

\begin{tabular}{|c|c|c|c|c|c|c|c|c|}
\hline \multirow[b]{2}{*}{$n 4, n 5, n 6$} & \\
\hline & $0,0,1$ & $0,1,1$ & $1,1,1$ & $1,1,0$ & $0,1,0$ & $0,0,0$ & $1,0,0$ & $1,0,1$ \\
\hline $0,0,1$ & {$[0,0,1,0,0,1]$} & {$[0,1,1,0,0,1]$} & {$[1,1,1,0,0,1]$} & {$[1,1,0,0,0,1]$} & {$[0,1,0,0,0,1]$} & {$[0,0,0,0,0,1]$} & {$[1,0,0,0,0,1]$} & {$[1,0,1,0,0,1]$} \\
\hline $0,1,1$ & {$[0,0,1,0,1,1]$} & {$[0,1,1,0,1,1]$} & {$[1,1,1,0,1,1]$} & {$[1,1,0,0,1,1]$} & {$[0,1,0,0,1,1]$} & {$[0,0,0,0,1,1]$} & {$[1,0,0,0,1,1]$} & {$[1,0,1,0,1,1]$} \\
\hline $1,1,1$ & {$[0,0,1,1,1,1]$} & {$[0,1,1,1,1,1]$} & {$[1,1,1,1,1,1]$} & {$[1,1,0,1,1,1]$} & {$[0,1,0,1,1,1]$} & {$[0,0,0,1,1,1]$} & {$[1,0,0,1,1,1]$} & {$[1,0,1,1,1,1]$} \\
\hline $1,1,0$ & {$[0,0,1,1,1,0]$} & {$[0,1,1,1,1,0]$} & {$[1,1,1,1,1,0]$} & {$[1,1,0,1,1,0]$} & {$[0,1,0,1,1,0]$} & {$[0,0,0,1,1,0]$} & {$[1,0,0,1,1,0]$} & {$[1,0,1,1,1,0]$} \\
\hline $0,1,0$ & {$[0,0,1,0,1,0]$} & {$[0,1,1,0,1,0]$} & {$[1,1,1,0,1,0]$} & {$[1,1,0,0,1,0]$} & {$[0,1,0,0,1,0]$} & {$[0,0,0,0,1,0]$} & {$[1,0,0,0,1,0]$} & {$[1,0,1,0,1,0]$} \\
\hline $0,0,0$ & {$[0,0,1,0,0,0]$} & {$[0,1,1,0,0,0]$} & {$[1,1,1,0,0,0]$} & {$[1,1,0,0,0,0]$} & {$[0,1,0,0,0,0]$} & {$[0,0,0,0,0,0]$} & {$[1,0,0,0,0,0]$} & {$[1,0,1,0,0,0]$} \\
\hline $1,0,0$ & {$[0,0,1,1,0,0]$} & {$[0,1,1,1,0,0]$} & {$[1,1,1,1,0,0]$} & {$[1,1,0,1,0,0]$} & {$[0,1,0,1,0,0]$} & {$[0,0,0,1,0,0]$} & {$[1,0,0,1,0,0]$} & {$[1,0,1,1,0,0]$} \\
\hline $1,0,1$ & {$[0,0,1,1,0,1]$} & {$[0,1,1,1,0,1]$} & {$[1,1,1,1,0,1]$} & {$[1,1,0,1,0,1]$} & {$[0,1,0,1,0,1]$} & {$[0,0,0,1,0,1]$} & {$[1,0,0,1,0,1]$} & {$[1,0,1,1,0,1]$} \\
\hline
\end{tabular}

Sobre esse espaço bidimensional, é possível desenhar um gráfico com as respectivas aptidões das combinações formando uma superfície tridimensional enrugada sobre esse espaço (Figura 3). 
Quando $K=0$, a contribuição de cada parte do sistema independe de todas as outras, e assim a superfície é suave, já que uma mudança em uma única parte deixa a contribuição das outras $N-1$ partes inalterada, conforme ilustrado na Figura 1(a). À medida que $K$ aumenta, uma mudança em uma parte altera a contribuição de $K$ outras partes do sistema. Assim, localizações vizinhas na paisagem não necessariamente têm valores de aptidão correlacionados, formando uma paisagem mais enrugada (Levinthal, 1997), conforme ilustrado na Figura 1(b).

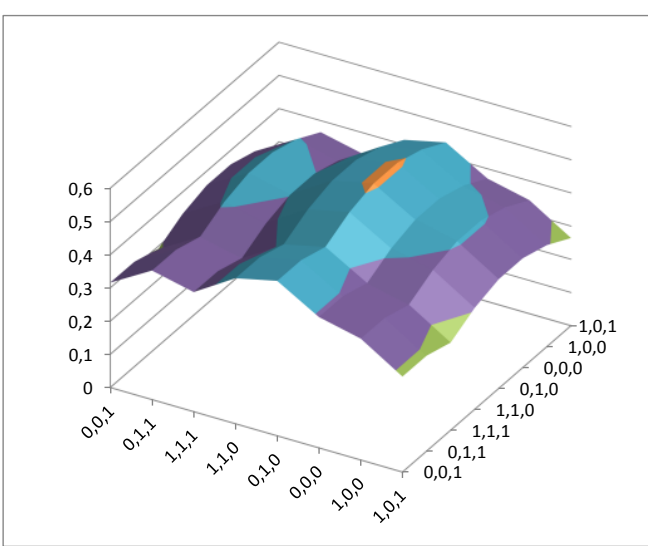

$\mathrm{N}=6 ; \mathrm{K}=0$

(a)

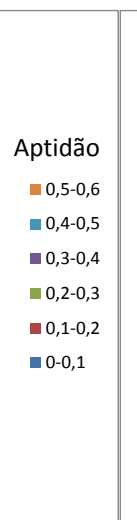

$0,5-0,6$

$0,3-0,4$

$0-0,1$

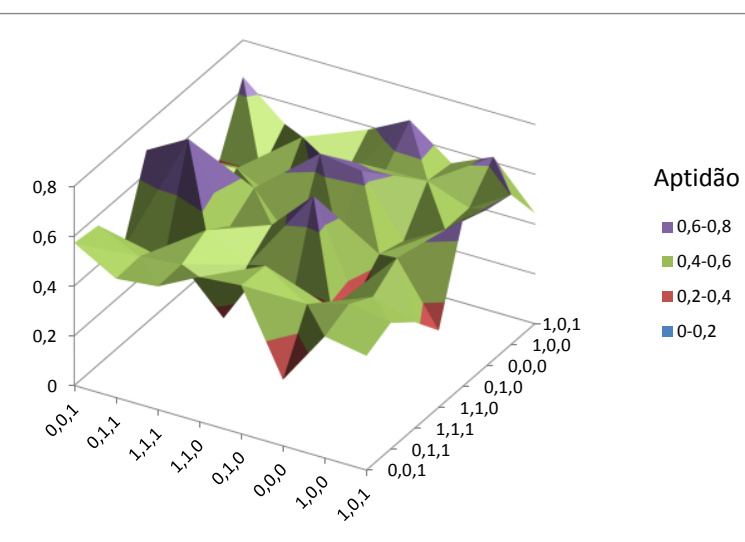

$\mathrm{N}=6 ; \mathrm{K}=5$

(b)

Figura 1: Superfície tridimensional sobre espaços com (a) $\mathbf{N}=6$ e $K=0$ e (b) $N=6 ; K=5$

Fonte: Elaborado pelos autores

No contexto organizacional, quando $\mathrm{K}$ é alto, o grau de interdependência interna também é alto entre, por exemplo, as $\mathrm{N}$ rotinas (Sorenson \& Baum, 2002), ou características da firma ou suas políticas estratégicas (Wall, 2014).

O cálculo da aptidão do modelo NK permite, pela variação de um único parâmetro $K$, obter paisagens diferentes. A aptidão $\mathrm{W}$ de determinada combinação de atributos $(\boldsymbol{x})$ do espaço é dada pela média das contribuições $\mathrm{w}_{\mathrm{i}}$ de cada um dos $N$ atributos do sistema:

$$
W=1 / N \Sigma_{-}(i=1)^{\wedge} N \text { N.W } W
$$

em que $w_{i}$ é a contribuição do i-ésimo atributo $\left(n_{i}\right)$. 
Por sua vez, a contribuição do $i$-ésimo atributo $\left(w_{i}\right)$ é gerada por números aleatórios, obtidos de uma distribuição uniforme entre 0 e 1 . Os números aleatórios são designados para cada uma das combinações possíveis do atributo $i$ e dos $K$ outros atributos.

O processo de evolução e adaptação de uma organização baseia-se na identificação de formas que geram maior aptidão organizacional na vizinhança. Assim, as organizações modificariam algum de seus atributos para assumir a nova forma com maior nível de aptidão. Esse processo também é chamado de "caminhada" já que a organização caminha pela paisagem em busca de locais de maior adaptação. Vale ressaltar que não se assume que a organização busca o maior gradiente de aptidão, isto é, a forma organizacional vizinha que propicia o maior valor de aptidão. Assume-se que a organização seleciona a primeira forma superior que ela descobre (Levinthal, 1997).

Outra forma de adaptação descrita por Levinthal (1997) é a "busca inovadora", em que a organização altera todos os seus atributos aleatoriamente em busca de uma posição de maior aptidão. Esse processo também é chamado de salto longo porque a organização salta de um local da paisagem para outro, sem ter "caminhado" pela superfície.

No nível populacional, Levinthal (1997) descreveu dois processos: o nascimento e a morte de organizações. Seguindo a lógica da biologia, a probabilidade de sobrevivência de um tipo de organização específica depende de sua aptidão em relação à maior aptidão da população. O número de organizações é mantido constante ao longo do tempo. Isso significa que o modelo NK não endereça questões relativas a dinâmicas de população ou competição em nichos (Levinthal, 1997).

Em relação ao nascimento de novas organizações, Levinthal (1997) especificou duas formas diferentes. Em uma delas, a nova organização assumia atributos totalmente aleatórios. Na segunda forma, a nova organização replicava a forma de uma organização existente. A probabilidade de uma nova organização ser criada de forma aleatória ou replicando uma forma existente depende da carga genética da população. A carga genética (P1) de uma população é um indicador estatístico que sumariza a aptidão geral de uma população, e é definida como um menos a 
razão entre a aptidão média da população e o valor máximo de aptidão (Levinthal, 1997; Kimura et al., 2006; Kimura, Perera \& Lima, 2010):

$$
P_{1}=1-\frac{\mu_{a p t i d a ̃ o}}{\operatorname{Max}_{i=1 \ldots 2^{N}}\left(W_{i}\right)}
$$

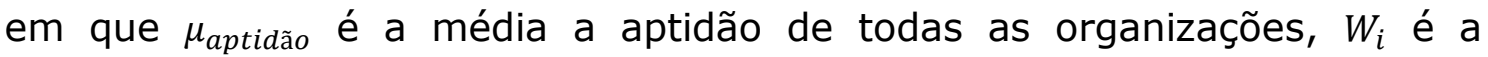
aptidão gerada pela i-ésima combinação genética.

Portanto, a carga genética pertence ao intervalo $[0,1]$, em que 0 indica uma população na qual todas as organizações têm a mesma aptidão, e 1 indica uma população com a diferença máxima entre a aptidão média e a maior aptidão possível (Levinthal, 1997).

Em uma população com maior nível médio de aptidão (menor carga genética), empresas antigas se sentiriam mais atraídas a replicar formas organizacionais existentes, e a probabilidade de a nova organização copiar uma organização existente é de um menos a carga genética. Em uma população com menor nível médio de aptidão (maior carga genética), é menos provável que empresas antigas utilizem formas existentes, e a probabilidade de a nova organização assumir uma configuração totalmente aleatória é igual à carga genética.

Para a estratégia, altos valores de carga genética caracterizam uma população com baixo nível de adaptação, e, portanto, com possibilidade de alcançar pontos de maior vantagem competitiva (Kimura, Perera \& Lima, 2010). Valores menores de carga genética caracterizam uma população com melhores níveis de adaptação, com organizações próximas a posicionamentos estratégicos melhores (Kimura et al., 2006). No Erro! Fonte de referência não encontrada., a seguir, sumarizam-se os conceitos do modelo NK original e a tradução desses conceitos para o gerenciamento.

\subsection{ADAPTAÇÃO DO MODELO NK PARA NEGÓCIOS INTERNACIONAIS}

As particularidades decorrentes da teoria e das estratégias das MNEs encontradas na literatura de negócios internacionais precisam ser consideradas para a utilização do modelo de Kauffman no campo de 
negócios internacionais. Para isso, cinco conceitos encontrados no contexto de estudo das MNEs serão utilizados para esse trabalho: (i) vantagem competitiva, (ii) diferença entre países, (iii) adaptação local, (iv) grau de adaptação local e (v) vantagem competitiva global.

\begin{tabular}{|c|c|c|}
\hline Modelo NK Original & Modelo NK para Gerenciamento & Notação \\
\hline $\begin{array}{l}\text { Número de partes, } \\
\text { aminoácidos ou genes }\end{array}$ & Número de atributos organizacionais & $N$ \\
\hline $\begin{array}{l}\text { Grau de acoplamento entre } \\
\text { as partes, ou epistasia entre } \\
\text { os genes }\end{array}$ & $\begin{array}{l}\text { Grau de interdependência ou } \\
\text { acoplamento entre os diversos } \\
\text { atributos da organização }\end{array}$ & $K$ \\
\hline $\begin{array}{l}\text { Parte do sistema/ } \\
\text { Aminoácido da proteína/ } \\
\text { Gene do genótipo }\end{array}$ & Atributos organizacionais & $n_{i}$ \\
\hline $\begin{array}{l}\text { Aptidão } \\
\text { fitness }\end{array}$ & Vantagem competitiva & $W=\frac{1}{N} \sum_{i=1}^{N} w_{i}$ \\
\hline Genótipo & Estrutura organizacional & $\boldsymbol{x}=\left(n_{1}, n_{2}, \ldots, n_{N}\right)$ \\
\hline $\begin{array}{l}\text { Contribuição à aptidão } \\
\text { Fitness contribution }\end{array}$ & $\begin{array}{l}\text { Contribuição para vantagem } \\
\text { competitiva }\end{array}$ & $w_{i}$ \\
\hline Carga genética & Carga genética & $\begin{array}{l}\quad \quad \boldsymbol{P}_{\mathbf{1}}=\mathbf{1}-\frac{\boldsymbol{\mu}_{\text {aptidão }}}{\boldsymbol{M a x}_{\boldsymbol{i}=\mathbf{1} \ldots \mathbf{2}^{N}\left(\boldsymbol{W}_{\boldsymbol{i}}\right)}} \\
\text { em que } \mu_{\text {aptidão é a média a }} \text { a } \\
\text { aptidão de todas as } \\
\text { organizações, } W_{i} \text { de é a } \\
\text { aptidão gerada pela } i \text {-ésima } \\
\text { combinação genética. }\end{array}$ \\
\hline
\end{tabular}

\section{Quadro 1: Conceitos do modelo NK originais e sua interpretação para o gerenciamento}

No modelo proposto, como no trabalho de Levinthal (1997), a organização possui uma estrutura organizacional representada pelo vetor $\boldsymbol{x}=\left(n_{1}, n_{2}, \ldots, n_{N}\right)$, em que $n_{i}$ é o $i$-ésimo atributo organizacional. A vantagem competitiva $W$ de uma determinada organização será definida conforme a equação Erro! Fonte de referência não encontrada.).

Como haverá diferentes paisagens, uma mesma estrutura organizacional, por exemplo $\boldsymbol{x}=(1,0, \ldots, 1,1,0)$, pode obter diferentes vantagens competitivas dependendo das características da paisagem. Então pode-se determinar que o que caracteriza cada paisagem é a Matriz de Contribuição à Vantagem Competitiva, $L$, de dimensão $2^{N} \times N$

$$
L=\left[\begin{array}{ccc}
l_{1,1} & \cdots & l_{1, N} \\
\vdots & \ddots & \vdots \\
l_{2^{N}, 1} & \cdots & l_{2^{N}, N}
\end{array}\right]
$$


em que o elemento $l_{j, i}$ é a contribuição do $i$-ésimo atributo organizacional para a j-ésima estrutura organizacional. Por exemplo, o elemento $l_{3,2}$ é a contribuição do atributo organizacional $n_{2}$ para a estrutura organizacional 3 . Um exemplo de Matriz de Contribuição à Vantagem Competitiva é apresentado na equação (4):

$$
L_{1}=\left[\begin{array}{lll}
0,02 & 0,11 & 0,36 \\
0,02 & 0,11 & 0,64 \\
0,02 & 0,48 & 0,36 \\
0,02 & 0,48 & 0,64 \\
0,78 & 0,11 & 0,36 \\
0,78 & 0,11 & 0,64 \\
0,78 & 0,48 & 0,36 \\
0,78 & 0,48 & 0,64
\end{array}\right]
$$

Conforme a teoria das MNEs, as diferentes características locais (variações culturais, preferências dos consumidores, aspectos legais e mercado de trabalho) fazem que determinadas estruturas organizacionais resultem em vantagens ou desvantagens. Como as estruturas organizacionais são determinadas pelos atributos organizacionais, pode-se inferir que os atributos organizacionais resultam em maiores ou menores vantagens dependendo do país (paisagem).

É possível então definir mais dois conceitos do modelo NK para as MNEs: (i) as paisagens do modelo original são as contribuições das características do país à aptidão para esse modelo, (ii) a diferença entre dois países é a diferença de suas Matrizes Contribuição, que também é uma matriz de dimensão $2^{\mathrm{N}} \times \mathrm{N}$ :

$$
\text { Matriz Diferença entre Países: } D=L_{\text {local } 1}-L_{\text {local } 2}
$$

Para traduzir a diferença entre locais em um escalar de modo que duas diferenças entre países possam ser comparadas de forma mais intuitiva, pode-se usar a seguinte expressão adaptada do cálculo do Standardized Root Mean Square Error (SRMSE) (Knudsen \& Fotheringham, 1986) e que basicamente expressa uma distância escalar entre matrizes: 


$$
\text { Diferença entre Locais: } d=\sqrt{\frac{\sum_{i=1}^{N} \sum_{j=1}^{2^{N}} d_{j, i}^{2}}{\left(N * 2^{N}\right)}}
$$

em que o elemento $d_{\mathrm{j}, \mathrm{i}}$ é o elemento da matriz diferença entre países $\mathrm{D}$ da linha j e coluna $i$.

Ativos específicos da firma precisam ser adaptados para estar adequados a novos locais devido a variações culturais, preferências dos consumidores, aspectos legais e mercado de trabalho.

Para a literatura, a adaptação local é entendida como modificações da estrutura organizacional para obtenção de vantagem competitiva em determinado local. No modelo proposto, a adaptação local ocorrerá pela modificação dos atributos organizacionais $n_{i}$ para determinado país. Para possibilitar que a adaptação local possa ocorrer em nosso modelo, mais três características do modelo NK para MNEs precisam ser definidas.

Primeiro, no modelo NK para MNEs, uma mesma organização poderá atuar em $p$ diferentes países. Segundo, a organização poderá ter diferentes estruturas organizacionais, uma em cada um desses países. Portanto, uma organização que atua em $p$ diferentes países, terá sua estrutura organizacional definida por $p$ diferentes vetores $\mathbf{x}_{\mathbf{p}}=\left(\mathrm{n}_{\mathrm{p}, 1,}, \mathrm{n}_{\mathrm{p}, 2}, \ldots, \mathrm{n}_{\mathrm{p}, \mathrm{N}}\right)$, em que $n_{p, i}$ é o $i$-ésimo atributo organizacional do $p$ ésimo país. Terceiro, se a organização pode ter diferentes estruturas organizacionais em diferentes países, então poderá ter diferentes vantagens competitivas $W_{p}$ nesses $p$ diferentes países onde atua:

$$
\mathrm{W}_{\mathrm{p}}=\frac{1}{\mathrm{~N}} \sum_{\mathrm{i}=1}^{\mathrm{N}} \mathrm{w}_{\mathrm{p}, \mathrm{i}}
$$

em que $W_{p}$ é a vantagem competitiva da organização no país $p$, e $w_{p, i}$ é a contribuição da $i$-ésima competência organizacional no $p$-ésimo país.

No modelo proposto, diferentes níveis de adaptação local poderão gerar diferentes vantagens à organização naquele país. Isso permite ao modelo contemplar adaptação local independentemente da causa do mesmo, seja ela deliberação estratégica da empresa, seja maior ou menor 
capacidade de transferência e adaptação de vantagens específicas da firma à realidade local.

Em relação ao posicionamento estratégico, isto é, a combinação de atributos organizacionais para obtenção de maior ou menor vantagem competitiva, a questão de controle deve ser encarada como o controle da MNE sobre seus atributos organizacionais $\left(n_{p, i}\right)$ dentro de sua estrutura organizacional $x_{p}=\left(n_{p, 1,}, n_{p, 2}, \ldots, n_{p, N}\right)$, em um país $p$.

O grau de adaptação local é moderado por diferentes mecanismos. Um deles é o dilema da multinacional e a necessidade de equilibrar a responsividade local minimizando perda da eficiência global (Bartlett \& Ghoshal, 1999). Outro mecanismo é a maior ou menor capacidade de adaptação dos ativos específicos da firma para estarem adequados a novos locais devido à diferença dos países (culturais, institucionais, etc.). Um terceiro mecanismo é a própria estratégia de internacionalização, em que a multinacional pode exercer diferentes níveis de controle sobre a adaptação local das subsidiárias. Seja por deliberação da matriz, seja por iniciativa das subsidiárias, seja por necessidade de integração global, seja por menor ou maior capacidade de adaptação dos ativos da firma, as multinacionais apresentam um grau de adaptação local e, portanto, esse modelo precisa definir esse conceito.

Define-se que o grau de adaptação local $G_{a, b}$ de uma subsidiária no país alvo $\lambda_{\mathrm{b}}$ em relação à sua matriz no país de origem $\lambda_{\mathrm{a}}$ será um valor entre 0 (nenhuma adaptação, estruturas organizacionais idênticas) e 1 (total adaptação, estruturas organizacionais totalmente diferentes) dado por:

$$
\mathrm{G}_{\mathrm{a}, \mathrm{b}}=\frac{\sum_{\mathrm{i}=1}^{\mathrm{N}}\left|\mathrm{n}_{\mathrm{a}, \mathrm{i}}-\mathrm{n}_{\mathrm{b}, \mathrm{i}}\right|}{\mathrm{N}}
$$

Em que $n_{a, i}$ é o $i$-ésimo atributo organizacional no país $a$ e $n_{b, i}$ é o $i$-ésimo atributo organizacional no país $b . N$ é número de atributos organizacionais. Como nesse modelo o processo de seleção se dará em nível global, não em nível local em um único país ou paisagem, a probabilidade de sobrevivência de uma de organização dependerá de sua vantagem competitiva global em relação à maior vantagem competitiva global da população de organizações. 
Seja $W_{p}$ a vantagem competitiva no $p$-ésimo país de uma organização que atua em $P$ países, sua vantagem competitiva global (Wglobal) será dada então por:

$$
\text { Wglobal }=\frac{1}{P} \sum_{\mathrm{i}=1}^{\mathrm{P}} \mathrm{W}_{\mathrm{p}}
$$

Como nesse modelo o processo de seleção se dará em nível global, a carga genética global será definida como:

$$
P_{\text {global }}=1-\frac{\mu_{\text {aptidão global }}}{\operatorname{Max}_{p=1 \ldots P} \operatorname{Max}_{i=1 \ldots 2^{N}}\left(W_{p, i}\right)}
$$

em que $\mu_{\text {aptidão global }}$ é a média da aptidão global de todas as organizações, $W_{p, i}$ é a aptidão gerada pela i-ésima combinação no $p$-ésimo país.

Ou seja, no processo de nascimento de novas organizações, a probabilidade de a nova organização copiar uma organização existente é de um menos a carga genética global. Logo, a probabilidade de a nova organização assumir uma configuração totalmente aleatória é igual à carga genética global.

\section{REGRAS DA SIMULAÇÃO BASEADA EM AGENTES}

No início da simulação, a configuração dos parâmetros é definida. Assim, um número $\mathrm{P}$ de países será gerado utilizando os parâmetros $\mathrm{N}$ (Número de atributos organizacionais) e K (Grau de interdependência). Para controlar a diferença entre os países, o parâmetro similaridade é definido. A similaridade é uma probabilidade no intervalo $[0,1]$. Quanto maior a similaridade, mais provável é a semelhança entre as Matrizes de Contribuição dos países, logo a diferença entre os países será menor. Assim, a "Diferença entre países" é uma variável calculada e poderá ser usada para análise no final da simulação.

Em sequência, será criada uma quantidade de agentes, determinada pelo "Número de organizações". No modelo, cada agente será uma organização, e cada organização será composta por $\mathrm{P}$ estruturas 
organizacionais, uma em cada país representando suas estruturas locais. Em sua criação, cada agente terá o parâmetro "Grau máximo de adaptação" definido aleatoriamente no intervalo [0, "Grau máximo de adaptação local da simulação"] com distribuição uniforme. Ainda na criação do agente, suas estruturas locais são igualadas a uma única configuração definida aleatoriamente. No Quadro 2, sumarizam-se os conceitos e as equações para a criação do modelo NK para as MNEs adotados neste trabalho.

A simulação será executada por uma quantidade finita de ciclos parametrizada pelo parâmetro "Número máximo de ciclos de simulação". A cada ciclo da simulação, cada uma das organizações (agentes) irá buscar posições de maior vantagem competitiva em cada um dos $P$ países. Essa busca acontecerá em cada país sequencialmente (por exemplo, país 1, 2, $\ldots, P)$. Ela será realizada pela avaliação da vantagem competitiva de cada uma das posições vizinhas naquele país específico.

Ao localizar uma posição de maior vantagem competitiva, a organização avaliará se a alteração de sua estrutura organizacional nesse país está dentro do limite do seu grau de adaptação máximo. Se a alteração estiver dentro do seu limite de adaptação, ela irá efetuar a alteração da estrutura e então passará para a busca no próximo país. 


\begin{tabular}{|c|c|}
\hline Modelo Adaptado & Notação \\
\hline $\begin{array}{l}\text { Matriz de Contribuição à Vantagem } \\
\text { Competitiva }\end{array}$ & $\begin{array}{l}\qquad L=\left[\begin{array}{ccc}l_{1,1} & \cdots & l_{1, N} \\
\vdots & \ddots & \vdots \\
l_{2^{N}, 1} & \cdots & l_{2^{N}, N}\end{array}\right] \\
\text { em que } l_{j, i} \text { é a contribuição da } \\
\text { i-ésima competência organizacional para a j- } \\
\text { ésima estrutura organizacional. }\end{array}$ \\
\hline Matriz de Diferença entre Países & $D=L_{\text {local } 1}-L_{\text {local } 2}$ \\
\hline Diferença entre Países & $\begin{array}{l}\qquad d=\sqrt{\frac{\sum_{i=1}^{N} \sum_{j=1}^{2^{N} d_{j, i}^{2}}}{\left(N * 2^{N}\right)}} \\
\text { em que o elemento } \mathrm{d}_{\mathrm{j}, \mathrm{i}} \text { é o elemento da } \\
\text { matriz D da linha j e coluna i. }\end{array}$ \\
\hline Países (paisagens) & $p_{1}, p_{2}, \ldots p_{p}$ \\
\hline Estrutura Organizacional Local & $\begin{array}{l}\boldsymbol{x}_{p}=\left(n_{p, 1,}, n_{p, 2}, \ldots, n_{p, N}\right) \\
\text { em que } n_{p, i} \text { é a i-ésima competência } \\
\text { organizacional no p-ésimo local. }\end{array}$ \\
\hline Grau de Adaptação Local & $\begin{array}{l}\mathbf{G}_{\mathrm{a}, \mathbf{b}}=\frac{\sum_{\mathbf{i}=\mathbf{1}}^{\mathbf{N}}\left|\mathbf{n}_{\mathbf{a}, \mathbf{i}}-\mathbf{n}_{\mathbf{b}, \mathbf{i}}\right|}{\mathbf{N}} \\
\text { em que } \mathrm{n}_{\mathrm{a}, \mathrm{i}} \text { é o }{ }^{\mathrm{i} \text {-ésimo atributo }} \\
\text { organizacional no país a e } \mathrm{n}_{\mathrm{b}, \mathrm{i}} \text { é a i-ésima } \\
\text { competência organizacional no local b. } \mathrm{N} \text { é } \\
\text { número de atributos organizacionais. }\end{array}$ \\
\hline Vantagem Competitiva no País & $\begin{array}{l}\qquad \mathbf{w}_{\mathbf{p}}=\frac{\mathbf{1}}{\mathbf{N}} \sum_{\mathbf{i}=\mathbf{1}}^{\mathbf{N}} \mathbf{w}_{\mathbf{p}, \mathbf{i}} \\
\text { em que } \mathrm{w}_{\mathrm{p}} \text { é a vantagem competitiva da } \\
\text { organização no país } \mathrm{p} \text { e } \mathrm{w}_{\mathrm{p}, \mathrm{i}} \text { é a contribuição } \\
\text { da i-ésima competência organizacional no p- } \\
\text { ésimo país. }\end{array}$ \\
\hline Vantagem Competitiva Global & $\begin{array}{l}\qquad \boldsymbol{W g} \text { lobal }=\frac{\mathbf{1}}{\boldsymbol{P}} \sum_{\mathbf{i}=\mathbf{1}}^{\mathbf{P}} \mathbf{W}_{\mathbf{p}} \\
\text { em que } W_{p} \text { é a vantagem competitiva no } p \text { - } \\
\text { ésimo país de uma organização que atua em } \\
\text { P países. }\end{array}$ \\
\hline Carga Genética Global & $\begin{array}{l}\qquad \boldsymbol{P}_{\text {global }}=1-\frac{\boldsymbol{\mu}_{\text {aptidão } \text { global }}}{\boldsymbol{M a x}_{\boldsymbol{p}=1 \ldots \boldsymbol{P}, \boldsymbol{i}=1 \ldots \mathbf{2}^{N}}\left(\boldsymbol{W}_{\boldsymbol{p}, \boldsymbol{i}}\right)} \\
\text { em que } \boldsymbol{\mu}_{\text {aptidão }} \text { global é a média da aptidão } \\
\text { global de todas as organizações, } \boldsymbol{W}_{\boldsymbol{p}, \boldsymbol{i}} \text { é a } \\
\text { aptidão gerada pela i-ésima combinação no } \\
\text { p-ésimo país. }\end{array}$ \\
\hline
\end{tabular}

\section{Quadro 2: Novos conceitos para o modelo NK para MNEs}

Se a alteração exceder o grau limite de adaptação da organização, ela não efetuará a alteração e passará para a busca do próximo país. Após terminar as buscas dos $\mathrm{P}$ países, a variável "Vantagem Competitiva Global" da organização é atualizada. Após cada uma das organizações terminar suas buscas nos $P$ países, o processo de seleção e surgimento de novas organizações é executado conforme foi especificado por Levinthal (1997), e 
a probabilidade de sobrevivência de uma organização será calculada a partir do maior valor de "Vantagem Competitiva Global". Com base nessas probabilidades de sobrevivência, serão "sorteadas" quais organizações "morrerão" e serão eliminadas da simulação, e quais continuarão.

Para manter a quantidade de organizações constante na simulação (definida pelo parâmetro "Número de organizações"), surgirão sempre novas organizações. Como em Levinthal (1997), ou a nova organização assumirá atributos totalmente aleatórios, ou replicará a forma de uma organização existente. A probabilidade de uma nova organização ser criada de forma aleatória ou replicando uma forma existente dependerá da carga genética global.

\subsection{IMPLEMENTAÇÃO DO MODELO}

O modelo foi desenvolvido na plataforma Repast Simphony 2.3.1, uma plataforma gratuita de modelagem e simulação baseada em agentes, com a qual foi possível construir o modelo do zero com grande flexibilidade e controle, além de se aproveitarem muitos recursos padrão para acessar comandos e parâmetros da simulação, visualizações e dados gerados, tudo facilitado por uma interface gráfica (Figura 4Erro! Fonte de referência não encontrada.).

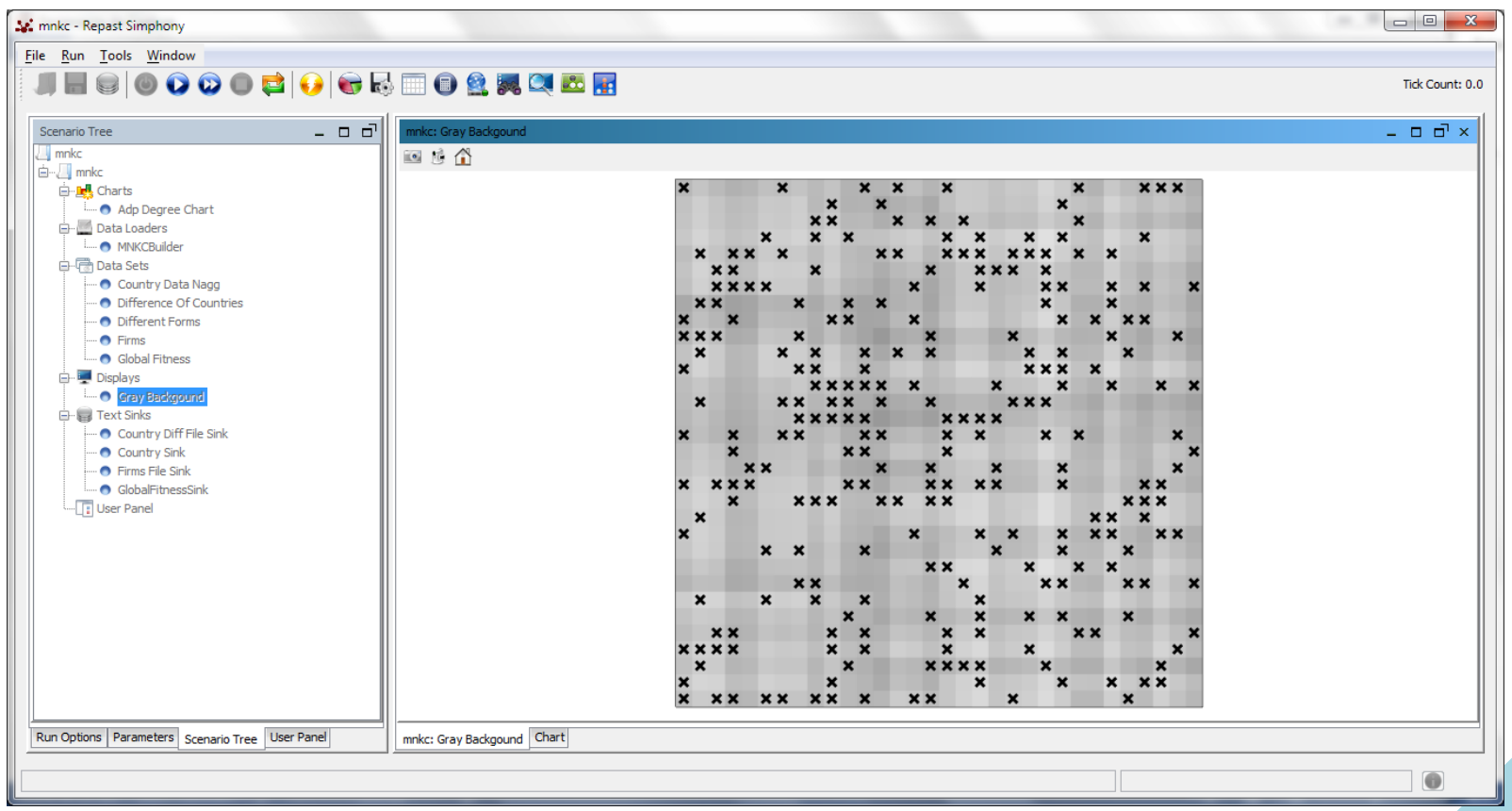

Figura 2: Painel de controle geral da plataforma Repast 
Fonte: Elaborado pelos autores

Na Figura 3, sumarizam-se cada ciclo de simulação e as regras das organizações.

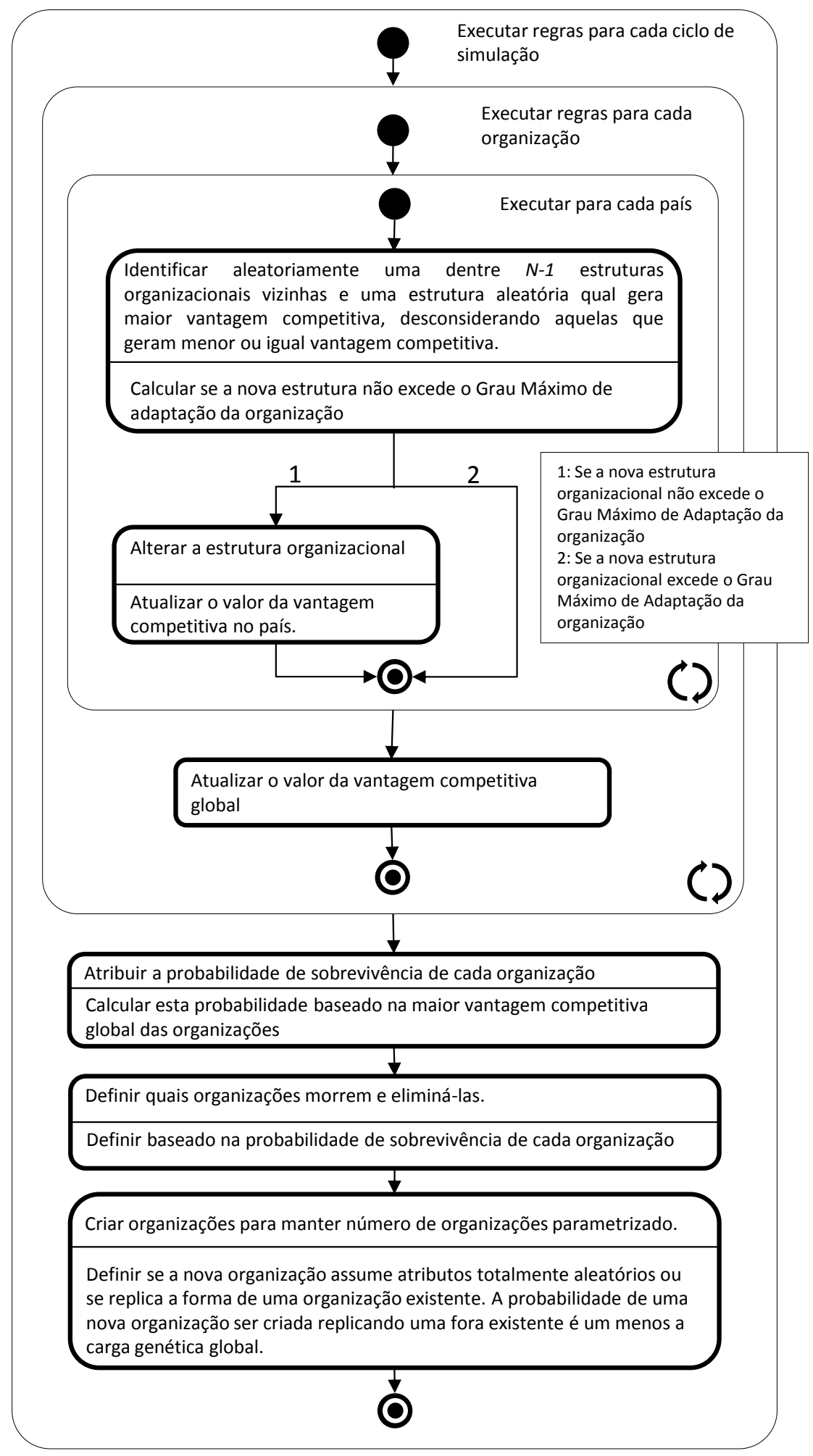

Figura 3: Processo de simulação 
Fonte: Elaborado pelos autores

\section{RESULTADOS DAS SIMULAÇÕES}

Para avaliar o modelo quando existe mais de um país, foram realizadas simulações com os parâmetros $\mathrm{P}=1,2,3$ e 4 (Número de países), $\mathrm{N}=10$ e $\mathrm{K}=8$. Para não haver influência da diferença entre países e da adaptação local, foram utilizados os parâmetros Similaridade $=1 \mathrm{e}$ Grau máximo de adaptação $=0$. Para cada valor de $P$, foram realizadas 100 repetições. Os resultados obtidos são apresentados na Tabela 1 e na Figura 4 e os valores apresentados são a média dessas 100 repetições.

Contatou-se que, do ponto de vista global, mesmo quando a diferença entre países é zero e sem adaptação local, i.e. quando a estrutura organizacional em cada um dos países é idêntica, é possível demonstrar que a vantagem competitiva global diminui com as inclusões de outros países.

A causa desse fenômeno, é o que Kauffman descreveu como a catástrofe da complexidade. Ela ocorre porque em cada interação a firma deve considerar as vantagens de $P$ países, que gera restrições conflitantes. Quando o número de restrições conflitantes aumenta, a escolha da melhor combinação de todos os $N$ atributos organizacionais dos $P$ países tende a degradar-se. Numericamente, os valores dos ótimos globais diminuem e tendem ao valor médio de vantagem competitiva do país.

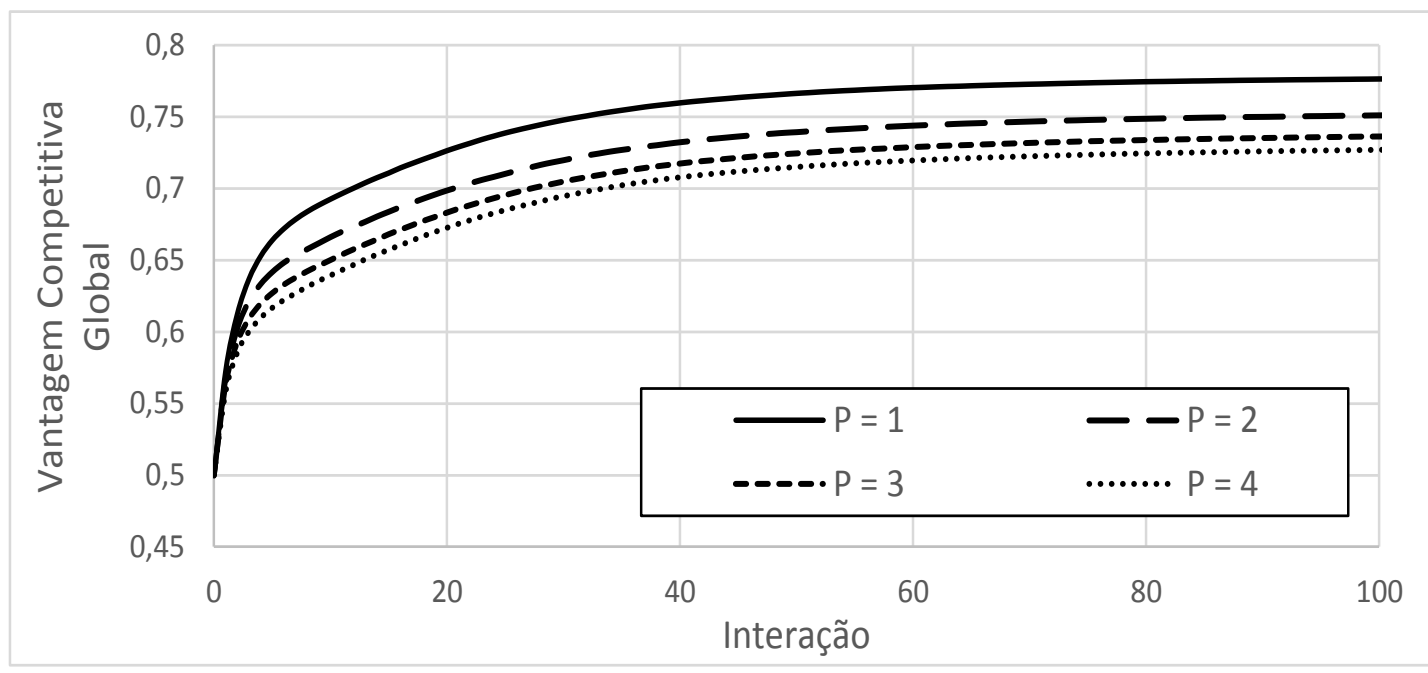

Figura 4: Vantagem Competitiva Global em função da quantidade de países $(P)$

Fonte: Elaborada pelos autores 
Tabela 1: Vantagem Competitiva Global em função da quantidade de países

\begin{tabular}{lllll}
\hline \multirow{2}{*}{ Interação } & $\mathrm{P}$ & \multicolumn{3}{l}{} \\
\cline { 2 - 5 } & 1 & 2 & 3 & 4 \\
\hline 0 & $0,500(0,010)^{*}$ & $0,500(0,009)$ & $0,500(0,008)$ & $0,500(0,008)$ \\
25 & $0,739(0,029)$ & $0,710(0,039)$ & $0,695(0,049)$ & $0,685(0,057)$ \\
50 & $0,766(0,031)$ & $0,739(0,040)$ & $0,725(0,050)$ & $0,715(0,057)$ \\
75 & $0,774(0,030)$ & $0,748(0,038)$ & $0,733(0,048)$ & $0,723(0,055)$ \\
100 & $0,776(0,029)$ & $0,751(0,038)$ & $0,736(0,048)$ & $0,727(0,054)$ \\
\hline
\end{tabular}

* O valor entre parênteses é o desvio padrão.

Do ponto de vista local, surgem novas formas organizacionais viáveis fora dos máximos locais, porque (a) a carga genética aumenta quando a quantidades de países $\mathrm{P}$ aumenta, conforme ilustrado na Figura 5, e (b) a média da quantidade de estruturas organizacionais distintas também aumenta conforme a quantidade de países aumenta, como mostra a Figura 6.

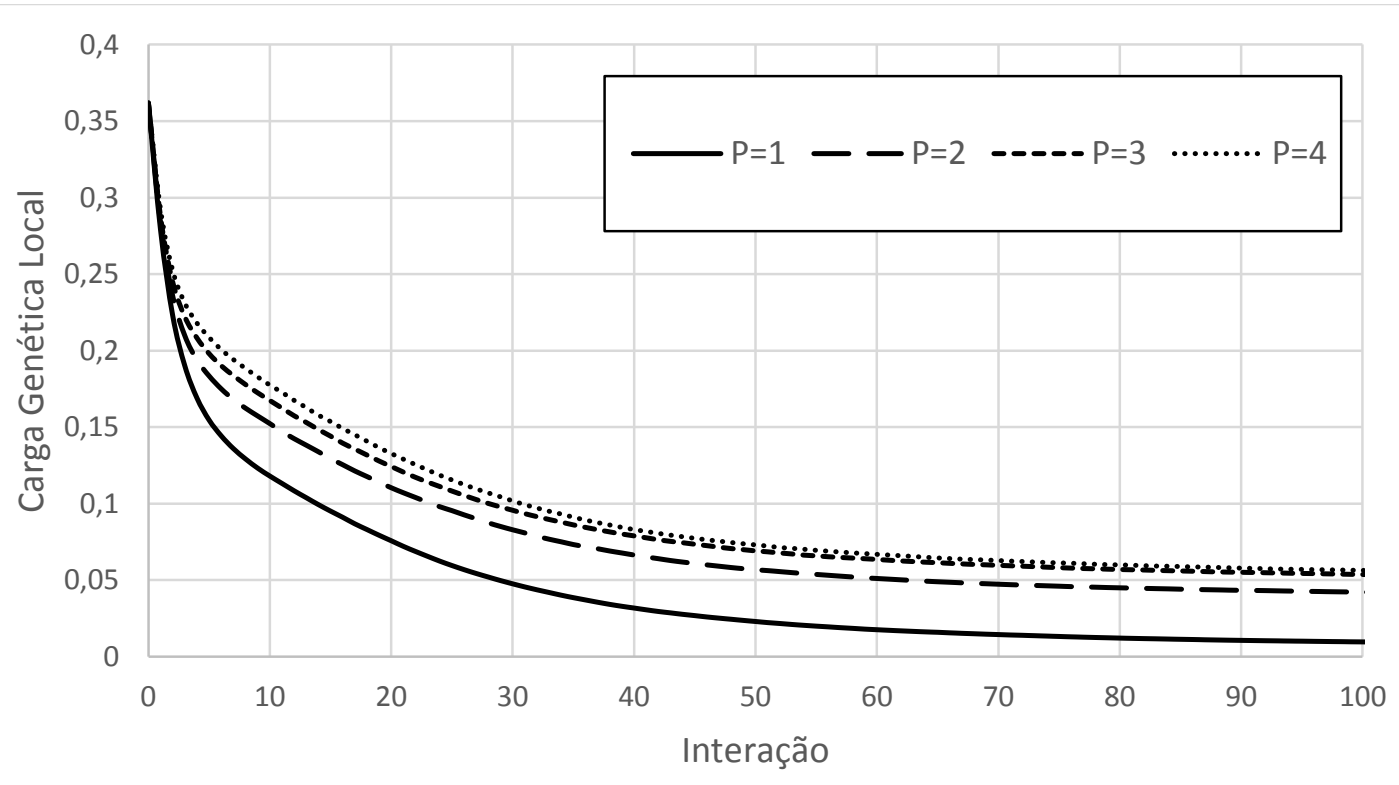

Figura 5: Carga Genética Local em função da quantidade de países

Fonte: Elaborada pelos autores 


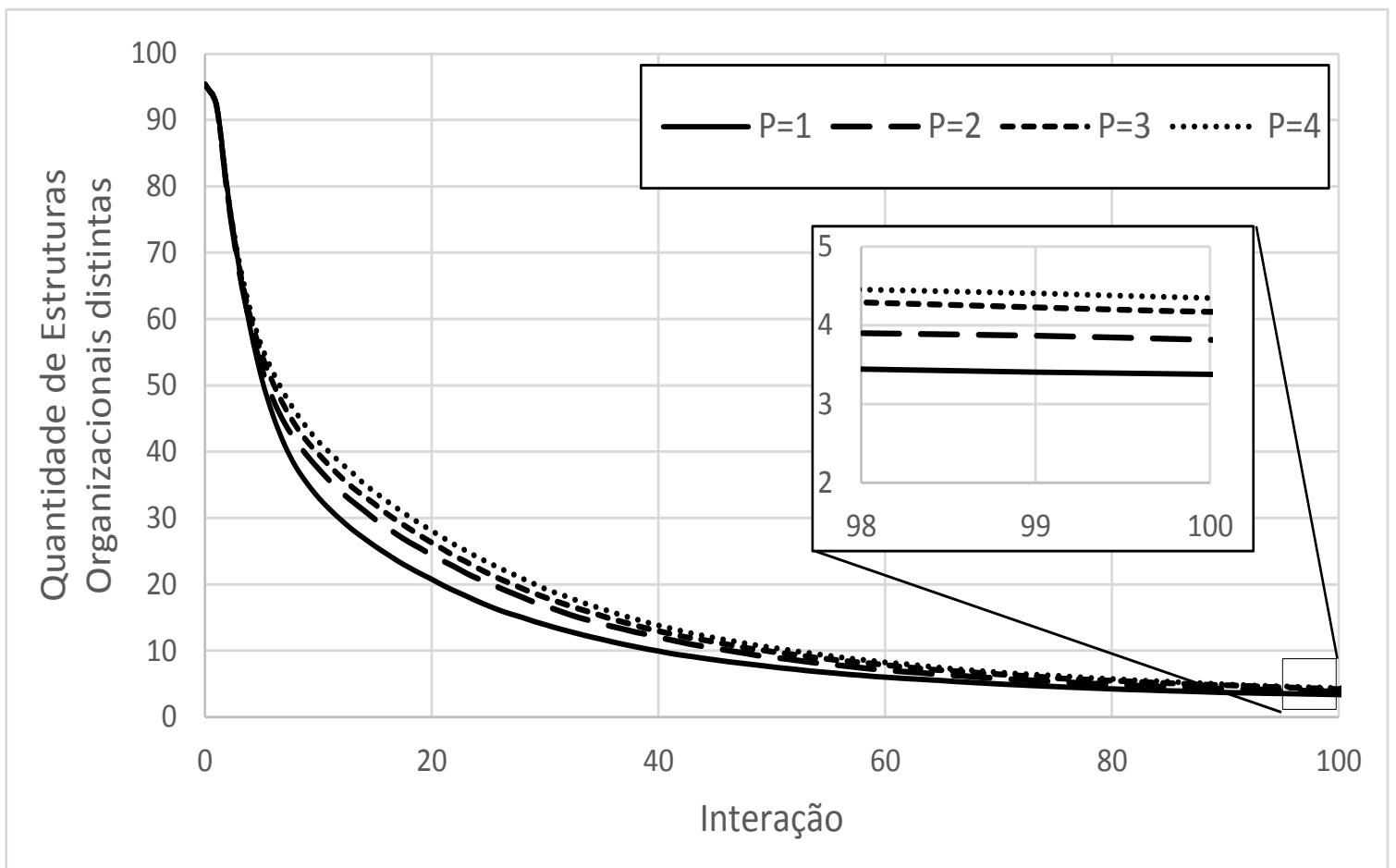

Figura 6: Quantidade de estruturas organizacionais distintas em função da quantidade de países

Fonte: Elaborada pelos autores

Na Tabela 2, sumarizam-se os valores obtidos na $100^{a}$ interação da simulação.

Tabela 2: Valores da Vantagem competitiva local, Carga Genética Local e Quantidade de estruturas Organizacionais Distintas em função da quantidade de países (P)

\begin{tabular}{c|c|c}
\hline \multicolumn{2}{c|}{$\begin{array}{c}\text { Interação }=100 \\
\text { Vantagem }\end{array}$} & $\begin{array}{c}\text { Quantidade de } \\
\text { Carga Genética Local } \\
\text { Competitiva Local }\end{array}$ \\
\hline $0,776(0,029)^{*}$ & $0,010(0,017)$ & $\begin{array}{c}\text { Estruturas Organizacionais } \\
\text { Distintas }\end{array}$ \\
$0,751(0,046)$ & $0,042(0,049)$ & $3,38(1,96)$ \\
$0,742(0,056)$ & $0,054(0,064)$ & $3,81(2,48)$ \\
$0,740(0,062)$ & $0,056(0,072)$ & $4,17(2,93)$ \\
\end{tabular}


* O valor entre parênteses é o desvio padrão.

Figura 7, apresentam-se representações visuais obtidas a partir das simulações. Nela, exibem-se formas organizacionais viáveis posicionadas nos máximos locais, quando $\mathrm{P}=1$ (a). Quando $\mathrm{P}=4$ (b), observa-se 0 surgimento de estruturas organizacionais viáveis não só em máximos locais, mas também em posicionamentos de menor vantagem competitiva local.

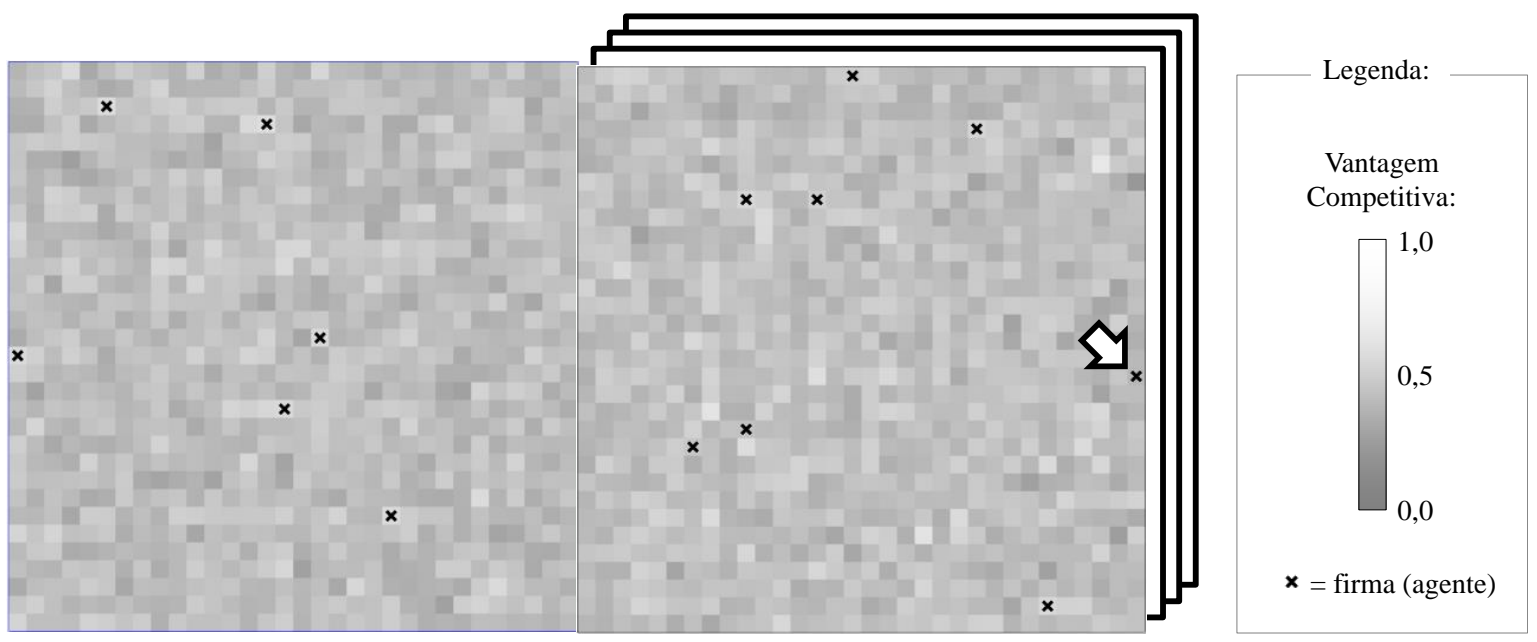

(a) $\mathrm{N}=10, \mathrm{~K}=8, \mathrm{P}=1$

(b) $\mathrm{N}=10 ; \mathrm{K}=8, \mathrm{P}=4$

Figura 7: Organizações (a) posicionadas nos máximos locais quando $P=0$ e (b) posicionadas nos máximos locais e fora dos máximos locais quanto $P=4$

Fonte: Elaborada pelos autores

Em resumo, verificou-se que, quando as organizações atuam em mais de um local, surgem novas formas organizacionais viáveis (Figura 6). Essas novas formas organizacionais obtêm menores níveis de vantagem competitiva local, conforme constatado pelo aumento da carga genética (Figura 5) e pela diminuição da média da vantagem competitiva local.

Isso demonstra que existem formas organizacionais que são inviáveis do ponto de vista local, mas que podem ser viáveis num contexto global. Assim, como ilustrado na Figura 8, observa-se o surgimento de novas organizações posicionadas estrategicamente fora do ótimo daquele país. 


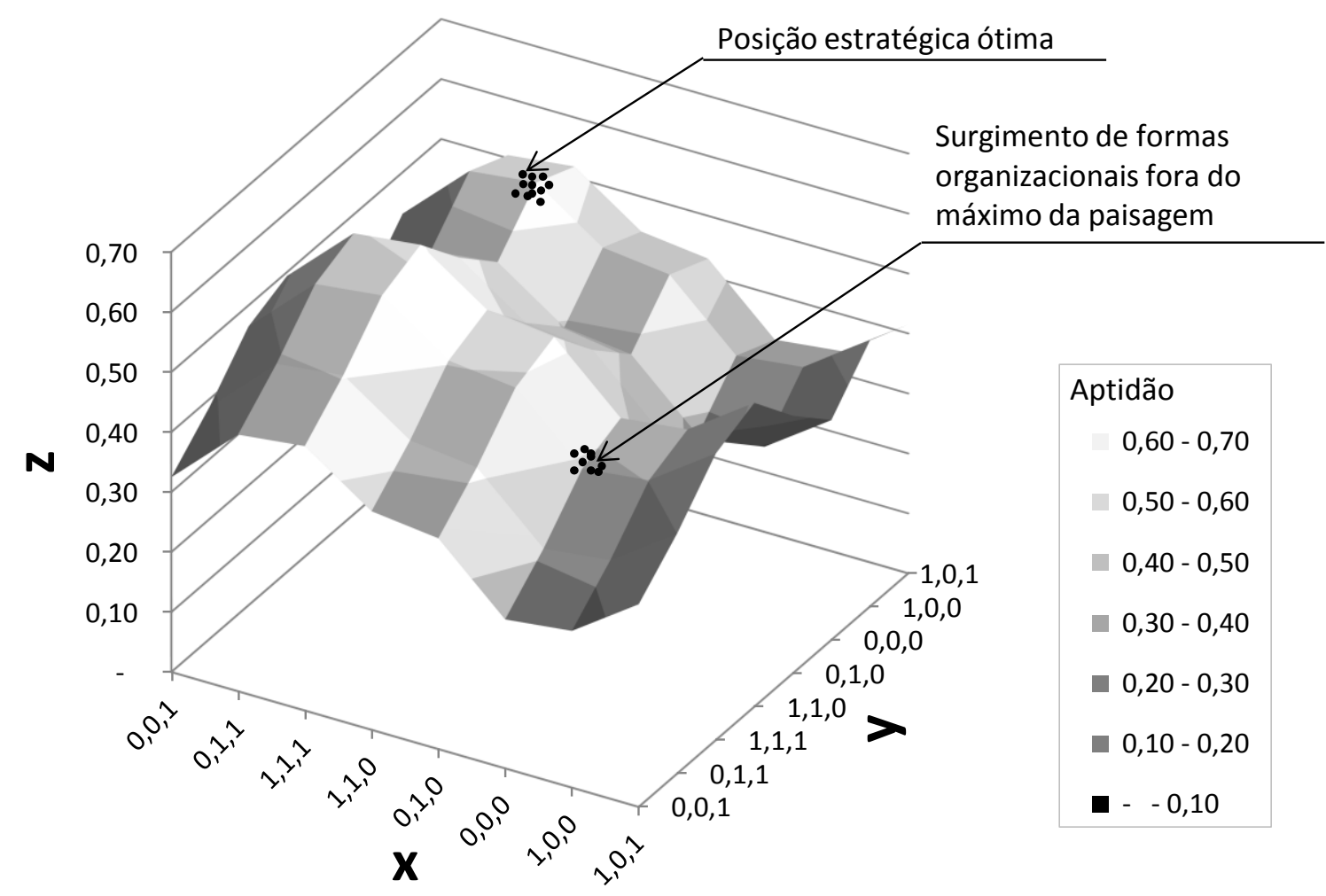

Figura 8: Surgimento de formas organizacionais viáveis fora do
máximo da paisagem

Fonte: Elaborada pelos autores

Para investigar o comportamento do modelo quando existe diferença entre os países e a adaptação local, foram realizadas simulações com os parâmetros Similaridade $=[0,0,25,0,45,0,6,0,75,0,85,0,95,0,975,1]$, e Grau máximo de adaptação $=[0,0,25,0,5,0,75,1]$. Os demais parâmetros foram fixados em $\mathrm{P}=4$ (Número de países), $\mathrm{N}=10$ e $\mathrm{K}=8$. Para cada combinação de Similaridade e Grau máximo de adaptação, foram realizadas 100 repetições.

Referentemente à diferença entre os países e à vantagem competitiva global, a Figura 9 foi elaborada para grau máximo de adaptação local $=0$ e 1 . O eixo $x$ é a similaridade entre os países, e o eixo y é a vantagem competitiva global média das 100 repetições. Na Figura 9, mostra-se que, quando se desconsidera o processo de adaptação local (grau máximo de adaptação local $=0$ ), conforme a similaridade entre os países aumenta, a média da vantagem competitiva global aumenta, o que é condizente com a teoria que subjaz ao modelo: quanto maior a diferença 
entre os países, menor a vantagem competitiva se não houver adaptação local. Esse fenômeno é chamado de liability of foreignness (LOF).

Por outro lado, quando o grau de adaptação máximo é 1 , isto é, as organizações podem ter estruturas organizacionais totalmente diferentes em cada um dos países, a diferença entre países não influencia a vantagem competitiva média. Isso significa que, caso fosse possível a adaptação local total sem nenhum tipo de ônus, as desvantagens de ser estrangeiro poderiam ser totalmente suprimidas pela adaptação local.

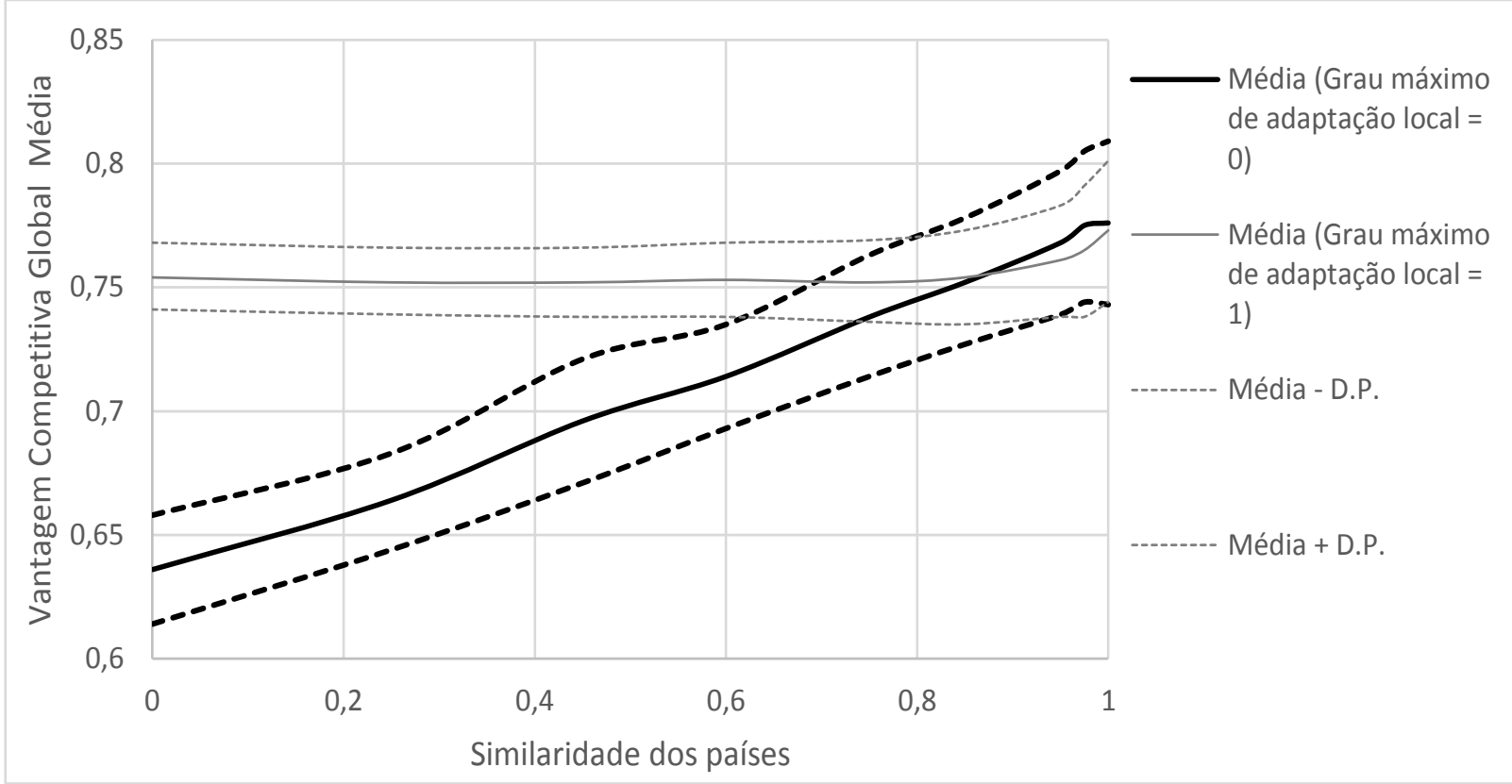

Figura 9: Vantagem Competitiva Global Média em função da similaridade dos países para Grau Máximo de adaptação local $=0$ e 1

Fonte: Elaborada pelos autores

Na Figura 10, apresenta-se a relação da média da quantidade de estruturas organizacionais distintas (eixo y) em função do grau máximo de adaptação local (eixo x). A partir dela, é possível observar que, para um maior grau máximo de adaptação local $(0,6$ a 0,1$)$, maior a quantidade de estruturas organizacionais. A recíproca também é verdadeira, assim, para um menor grau máximo de adaptação local (0 a 0,4), menor a quantidade de estruturas organizacionais. Também se constata que, para um dado grau máximo de adaptação local, quanto maior a diferença entre os países, maior a quantidade de estruturas organizacionais distintas 


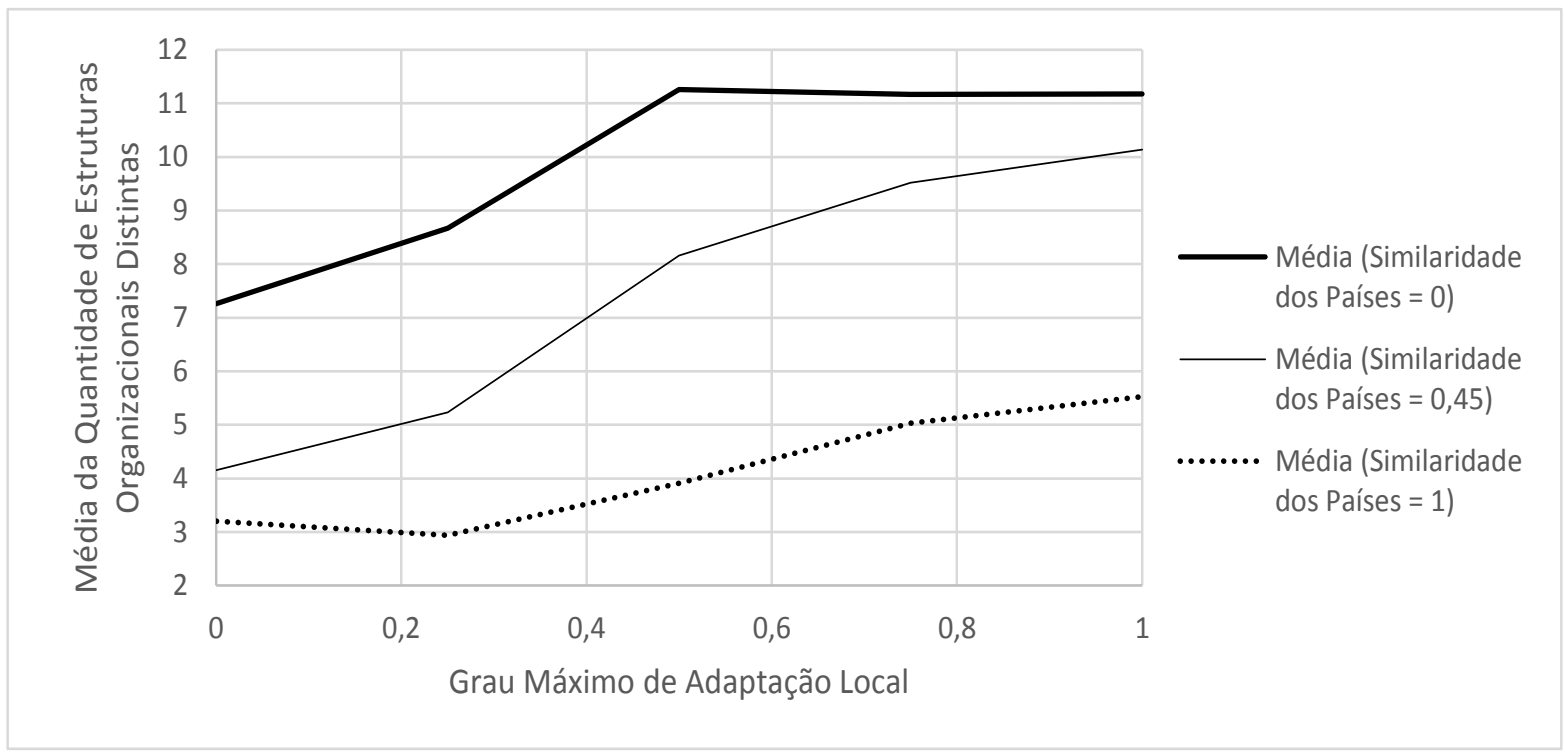

Figura 10: Média da quantidade de estruturas organizacionais distintas em função do grau Máximo de adaptação local para similaridade dos países $=0,0,45$ e 1

Fonte: Elaborada pelos autores

\section{CONCLUSÕES}

No modelo apresentado, foi possível notar que o aumento da quantidade de países e a possibilidade de adaptar a estrutura local em cada um deles são equivalentes ao aumento de restrições conflitantes, que faz com que a vantagem competitiva obtida das decisões estratégicas se degrade e tenda à média. Isso ocorre mesmo quando não há diferença entre países, logo é uma desvantagem não decorrente do liability of foreignness, mas decorrente exclusivamente da catástrofe da complexidade.

Também foi possível observar o surgimento do fenômeno liability of foreignness no comportamento do modelo apresentado. Ao se tirar a possibilidade de adaptação local, conforme a diferença entre os países aumenta, menores são os níveis médios de vantagem competitiva global observados.

Com relação à carga genética, os resultados das simulações mostraram que as organizações, pelo processo de adaptação local, conseguem posicionar-se mais próximas às posições estratégicas ótimas, e, quanto maior for seu grau de adaptação local, melhor o fazem. A recíproca 
também é verdadeira, já que o modelo mostrou que, na ausência de adaptação local, quanto maior a diferença entre os países, mais inaptas ficam as organizações de posicionar-se próximas às posições estratégicas ótimas.

Também foi possível observar que, quanto maior o grau máximo de adaptação local, maior será a quantidade de estruturas organizacionais distintas para qualquer nível de similaridade dos países. Ademais, quanto mais diferentes os países, maior a quantidade de estruturas organizacionais viáveis, para qualquer grau máximo de adaptação local.

Isto mostra que, se por um lado o processo de mimetismo organizacional e de seleção natural dos mais aptos faz com que as organizações se tornem mais homogêneas (menor quantidade de estruturas organizacionais distintas), qualquer fator que iniba a adaptação local ou que gere a diferença entre os países faz uma pressão contra essas forças e gera heterogeneidade na população das organizações (maior quantidade de estruturas organizacionais distintas).

Em resumo, foi possível demonstrar que o modelo NK pode ser estendido para atender agendas específicas relacionadas a estratégias de negócios internacionais, e que importantes insights se originam na análise dos resultados do modelo. Além disso, o trabalho fornece uma ferramenta prática para que outros pesquisadores possam verificar, melhorar e estender o modelo desenvolvido e os conceitos nele implementados. O código e os programas implementados neste trabalho podem ser compartilhados mediante solicitação aos autores. 


\section{REFERÊNCIAS}

Anderson, P. (1999). Perspective: complexity theory and organization science. Organization Science, 10(3), 216-232.

Bartlett, C. A., \& Ghoshal, S. (1999). Managing across borders: the transnational solution. UK: Taylor \& Francis.

Berry, H., Guillén, M. F., \& Zhou, N. (2010). An institutional approach to cross-national distance. Journal of International Business Studies, 41(9), 1460-1480.

Caldart, A. A., \& Ricart, J. E. (2007). Corporate strategy: an agent-based approach. European Management Review, 49(2), 107-120.

Davis, J. P., Eisenhardt, K. M., \& Bingham, C. B. (2007). Complexity theory, market dynamism, and the strategy of simple rules. Proceedings of DRUID Summer Conference, Portugal.

Dunning, J. H., \& Lundan, S. M. (2008). Institutions and the OLI paradigm of the multinational enterprise. Asia Pacific Journal of Management, 25(4), 573-593.

Ganco, M., \& Hoetker, G. (2009). NK modeling methodology in the strategy literature: bounded search on a rugged landscape. Research Methodology in Strategy and Management, 5, 237-268.

Hofstede, G. (1980). Culture's consequences: international differences in work-related values. Thousand Oaks, CA: Sage.

Holland, J. H. (1992). Complex adaptive systems. Daedalus, 121(1), 17-30.

Johanson, J., \& Vahlne, J.-E. (2009). The Uppsala internationalization process model revisited: from liability of foreignness to liability of outsidership. Journal of International Business Studies, 40(9), 14111431.

Kauffman, S. A. (1993). The origins of order: self-organization and selection in evolution. Oxford: Oxford University Press.

Kimura, H., Perera, L. C. J., \& Lima, F. G. (2010). Teoria da complexidade e paisagens de adaptação: aplicações em estratégia. Revista de Administração, 45(3), 238-254.

Kimura, H. et al. (2006). Paisagens de Kauffman e posicionamento estratégico sob condições de risco. Anais do Seminários em Administração - SemeAd, 9, São Paulo, SP, Brasil..

Knudsen, D. C., \& Fotheringham, A. S. (1986). Matrix comparison, goodness-of-fit, and spatial interaction modeling. International Regional Science Review, 10(2), 127-147. 
Kogut, B., \& Singh, H. (1988). The effect of national culture on the choice of entry mode. Journal of International Business Studies, 19(3), 411-432.

Kostova, T., Roth, K., \& Dacin, M. T. (2008). Institutional theory in the study of multinational corporations: a critique and new directions. Academy of Management Review, 33(4), 994-1006.

Levinthal, D. A. (1997, July). Adaptation on rugged landscapes. Management Science, 43(7), 934-950.

Macal, C. M., \& North, M. J. (2009, Winter). Agent-based modeling and simulation. Proceedings of the Conference on Winter Simulation, Austin, TX, USA.

Man Joe Ma, A., \& Osula, B. (2011). The Tao of complex adaptive systems (CAS). Chinese Management Studies, 5(1), 94-110.

McKelvey, B. (1999). Avoiding complexity catastrophe in coevolutionary pockets: strategies for rugged landscapes. Organization Science, 10(3), 294-321.

Miller, J. H., \& Page, S. E. (2009). Complex adaptive systems: an introduction to computational models of social life. Princeton, $\mathrm{NJ}$ : Princeton University press.

Pina e Cunha, M., Vieira da Cunha J.; Wilding, R. (2006). Towards a complexity theory of strategy. Management Decision, 44(7), 839-850.

Porter, M. E., \& Siggelkow, N. (2008). Contextuality within activity systems and sustainability of competitive advantage. The Academy of Management Perspectives, 22(2), 34-56.

Porter, M. E. (1991). Towards a dynamic theory of strategy. Strategic Management Journal, 12(S2), 95-117.

Siggelkow, N., \& Levinthal, D. A. (2003). Temporarily divide to conquer: centralized, decentralized, and reintegrated organizational approaches to exploration and adaptation. Organization Science, 14(6), 650-669.

Sorenson, O., \& Baum, J. (2002). Interorganizational complexity and computation. In J. Baum (Ed.), Companion to organizations (pp. 664685). Malden, MA: Blackwell.

Tallman, S. B., \& Yip, G. S. (2001). Strategy and the multinational enterprise. In A. M. Rugman, \& T. L. Brewer (Eds.), The Oxford handbook of international business (pp. 317-348). Oxford: Oxford University Press.

Teece, D. J. (2006). Reflections on the Hymer thesis and the multinational enterprise. International Business Review, 15(2), 124-139.

Vidgen, R., \& Padget, J. Sendero: an extended, agent-based implementation of Kauffman's NKCS model. Journal of Artificial Societies and Social Simulation, 12(4), 8. 
Wall, F. (2014). Agent-based modeling in managerial science: an illustrative survey and study. Review of Managerial Science, 1-59.

Wright, S. (1932). The roles of mutation, inbreeding, crossbreeding, and selection in evolution. Proceedings of the International Congress of Genetics, 6. 